\title{
INTRUSION OF MOISTURE OVER THE KATHMANDU VALLEY FROM SOUTHERN PLAIN
}

\author{
Sangeeta Maharjan \\ National Atmospheric Resource and Environmental Research Laboratory (NARERL) \\ Central Department of Physics, Tribhuvan University \\ sangeetamaharjan@gmail.com
}

\begin{abstract}
Preliminary study on moisture transport along with the prevailing southwesterly wind system into the Kathmandu valley from southern plains via mountain gaps has been carried with the application of Weather Research and Forecasting (WRF) Modeling System. Intrusion of wind in the form of combined valley and plain-to-plateau winds from southern plain have been discussed in the past but the transport of moisture is yet to be understood. The present study reveals that significant amount of moisture intrudes into the valley from the southern plain, particularly, during the late afternoon time. Preliminary findings of this study are expected to be an excellent starting points for further in-depth studies complemented with detail field observations.
\end{abstract}

Keywords:- Upvalley wind, Mountain wind, WRF model and Kathmandu valley.

\section{INTRODUCTION}

The Kathmandu valley, a bowl shaped elevated valley, surrounded by other lower valleys, is located in the middle hills of central region of Nepal Himalaya. The valley is said to be executing a plateau-basin dual nature, i.e., it behaves as a plateau during the daytime by bringing the regional air masses up into the valley and as a basin during a nighttime by forming a deep cold air pool (Regmi et al., 2003). The characteristic afternoon time near surface wind systems over the Kathmandu valley comprised of southwesterly and northwesterly. These two dominating wind system merge into westerly wind in the central area of the Kathmandu basin and that the westerly channel out into the eastern neighboring valley. The southwesterly is comprised of valley and plain-to-plateau winds from the southern plain (Regmi et al., 2003).

Moreover, a recent study on the atmospheric transport processes over the Hetauda valley, located in the southern plain (Acharya et al., 2014) further revealed that intrusion of upvalley and plain-to-plateau wind into the Kathmandu valley accompanied with massive scale mountain waves and formation of vertical rotor over the Hetauda valley. The southwesterly may bring significant amount of lowland air pollutants up into the Kathmandu valley (Regmi et al., 2003; Kitada and Regmi, 2003; Acharya et al., 2014).

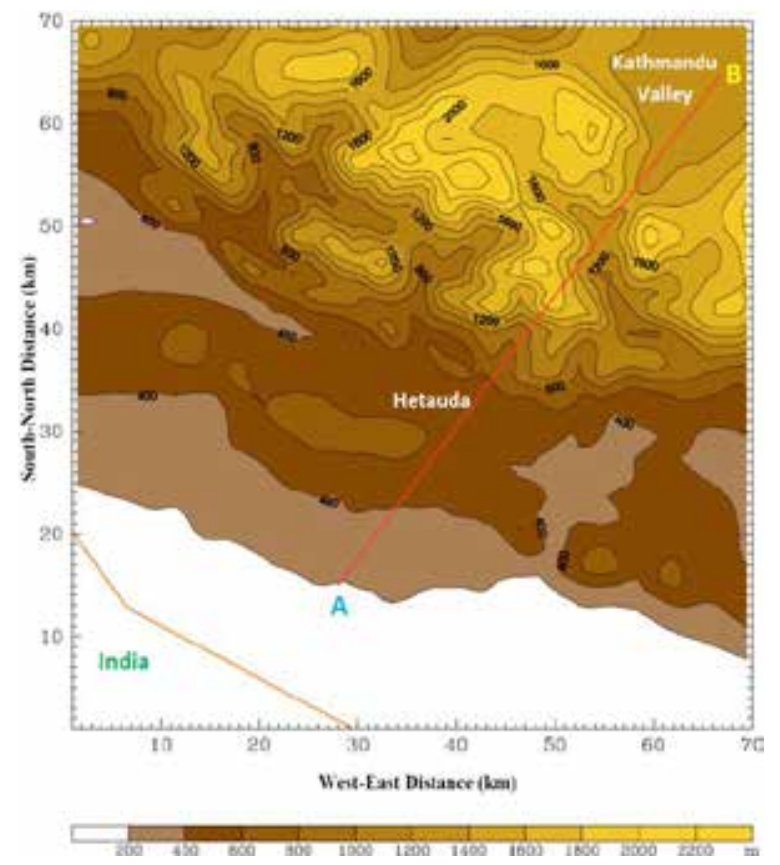

Figure 1: 2D-topography of the study area enclosed by the finest calculation domain. The line $A-B$ represents one of the major paths through with meteorological fields intrude into the Kathmandu valley from southern plain.

However, intrusion of moisture from southern plain up into the Kathmandu valley was not the part of previous studies although spatial and temporal distributions of moisture over the Kathmandu valley have been extensively studied by Maharjan and Regmi, 2014. In this paper, we will discuss the 
transport of moisture up into the Kathmandu valley from southern plain, particularly, the Heatuda valley which can have profound effect on the prevailing weather and climate over the Kathmandu valley. Scrutiny of temperature distribution in between the southern plain and the Kathmandu has also carried along as it largely affects the moisture holding capacity of the air.

\section{METHODS}

The transport of heat and moisture over the Kathmandu from Hetauda valley and its surroundings has been numerically simulated with the application of the WRF Modeling System (Skamarock et al. 2008). The simulation was performed for the period of 12 May 20130000 UTC to the 19 May 2013 0000 UTC. A triply nested domain was configured, with grid spacing of $9 \mathrm{~km}$ for the outermost domain, $3 \mathrm{~km}$ for the fine domain, and $1 \mathrm{~km}$ for the innermost domain. For vertical spacing, 35 levels were choosen. Specific physics options selected include the Thompson scheme, the Noah land surface model, the YSU boundary layer scheme, and the Kain- Fritsch cumulus parameterization for the outermost domain only. The model was initialized with horizontal resolution 6 hourly meteorological data from National Centers for Environmental Prediction (NCEP) and the 24 categories land use and 30 second terrain elevation data by United States Geological Survey (USGS).

\section{RESULTS}

A weeklong simulated meteorological fields showed a high diurnal periodicity in their characteristics. This is why; we choose a single day to describe the heat and moisture transport characteristics into to Kathmandu valley form southern plane, i.e., 16 May 2013. The day is expected to be a representative for the pre-monsoon period.

\subsection{Moisture Transport}

Figure 2 shows diurnal variations in the crosssectional distributions of potential temperature and relative humidity along the line A-B (see Figure 2) that connects Hetauda and Kathmandu valleys. During the midnight period, the air mass of Kathmandu valley appears to be relatively humid compared to the air mass over the southern plain and over Hetauda valley. The near surface relative humidity over the central Kathmandu valley is about $20 \%$ than over the southern plain but upper air masses over both the areas appears to be more or less equally humid (see Figure $2 \mathrm{a}$ ). In the early morning (see Figure 3c), the near surface humidity level over the Kathmandu valley dramatically decreases and an appreciable advection of moist air commences from Hetauda valley towards the Kathmandu valley. Intermingling with the humid air masses aloft the southern rim of Kathmandu valley, the moist air mass over the Hetauda valley intrudes into the Kathmandu valley through the southwestern mountain gaps pushing the relatively dry air mass towards the central area (see Figure 2c-f).

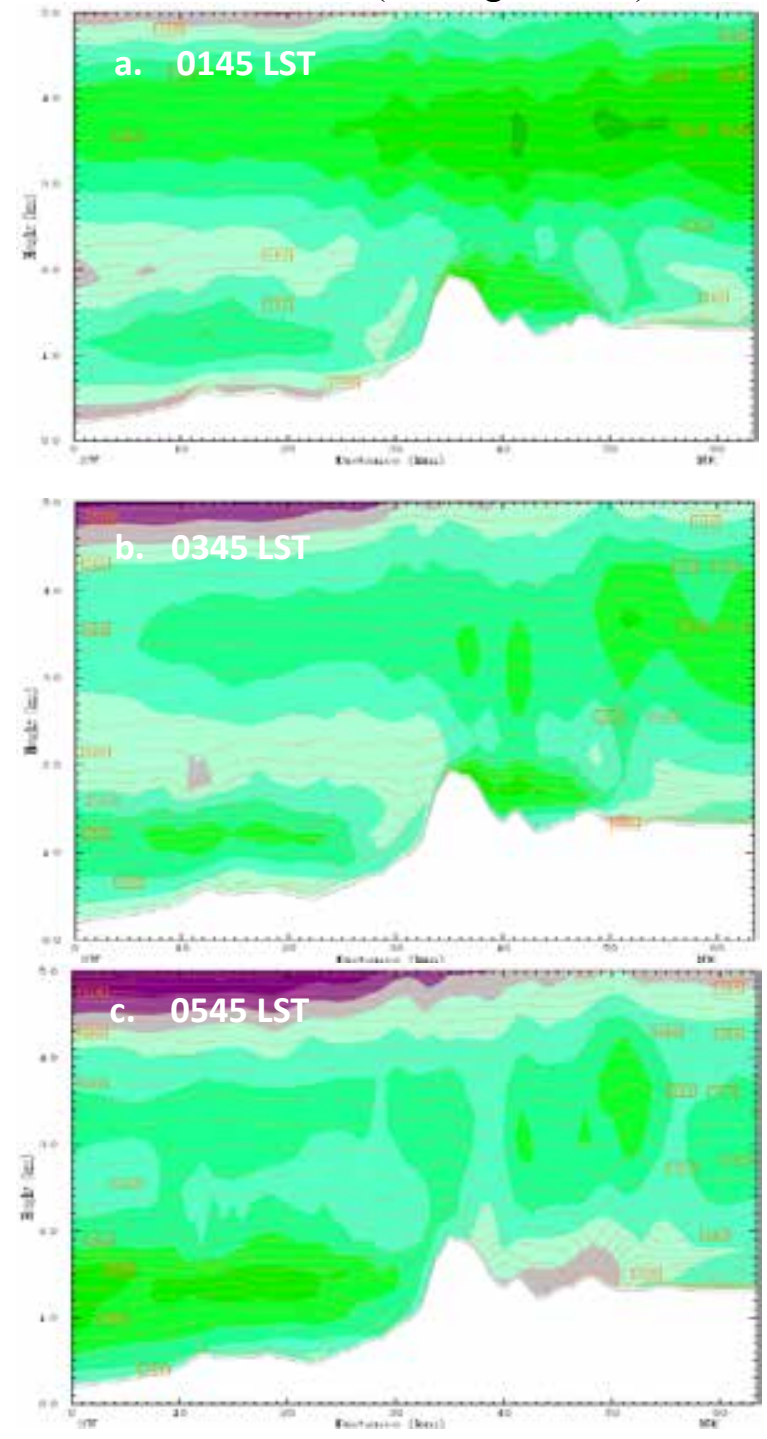



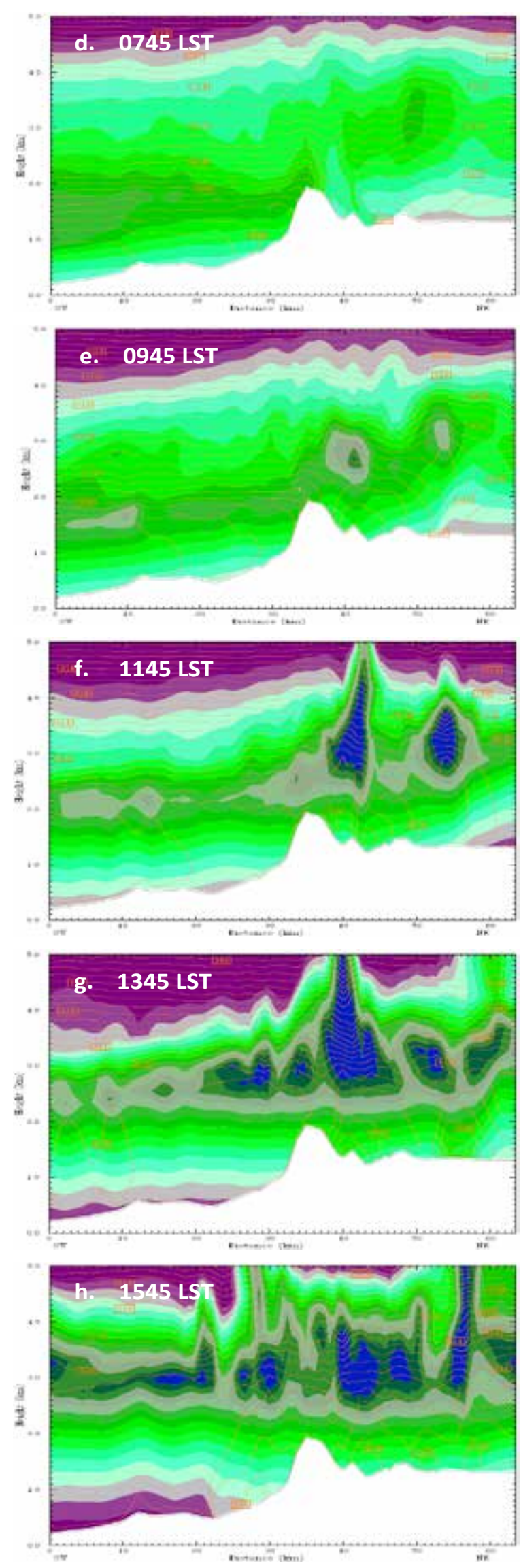
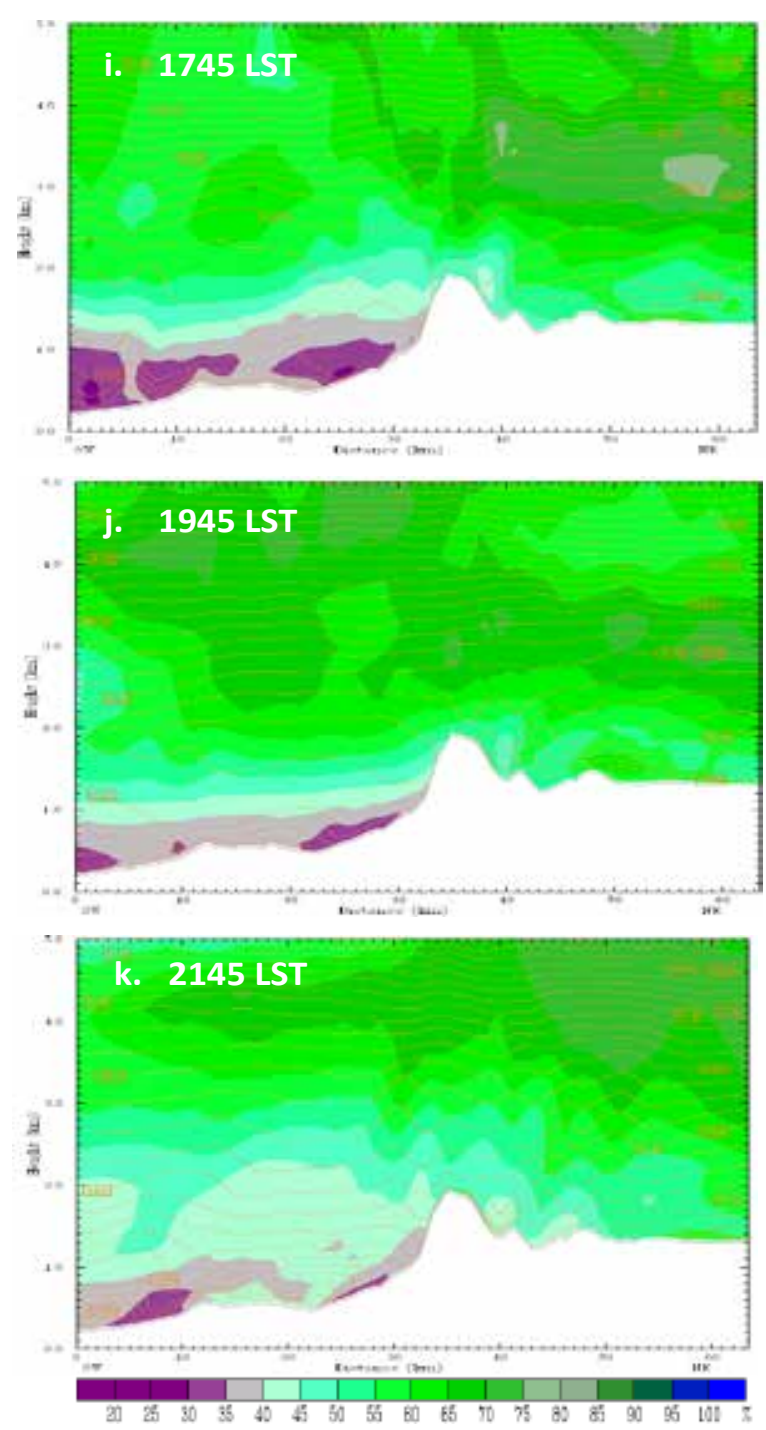

Fig. 2: Vertical cross-sectional distributions of moisture along the line $\mathrm{A}-\mathrm{B}$ that joins Kathmandu and Hetauda.

The advection of humid air mass into the Kathmandu valley continues until late afternoon (Fig. 2d-i). The humidity level of this air mass may remain in between $80-100 \%$.

In the evening, the humidity level of advected air mass starts to decease and gradually returns to the more or less the same situation described earlier close to midnight. In consideration with the weeklong diurnal variation of relative humidity (not shown), it can be said that there is little day-to-day variation in the transport of moisture from Hetauda area up into the Kathmandu valley. 


\section{TEMPERATURE DISTRIBUTION}

Figure 3 shows the diurnal variation of vertical crosssectional distributions of temperature superimposed with potential temperature contours along A-B cross-section as defined previously. During midnight and early morning, the Kathmandu valley is seen to be stably stratified forming a cool air pool with near surface temperature varying between 20 to $18^{\circ} \mathrm{C}$ (see Figure 3a-b) whereas the temperature over the Hetauda valley or southern plain appears to be close to $25^{\circ} \mathrm{C}$ in consistent with the findings of Regmi et al. (2003). However, the situation over the Hetauda valley is significantly different since the mixing activities over the Hetauda valley are not fully suppressed as in Kathmandu valley.
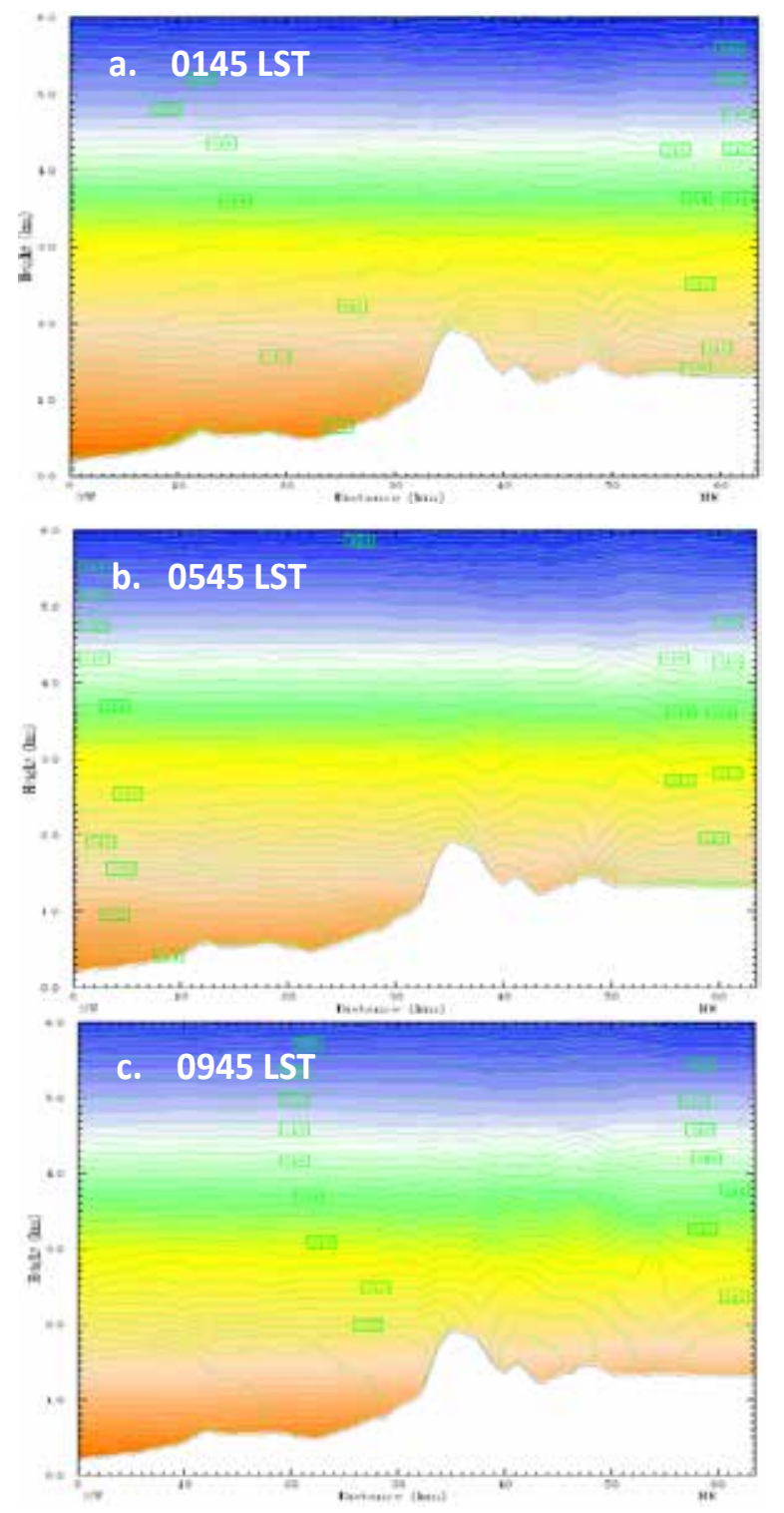
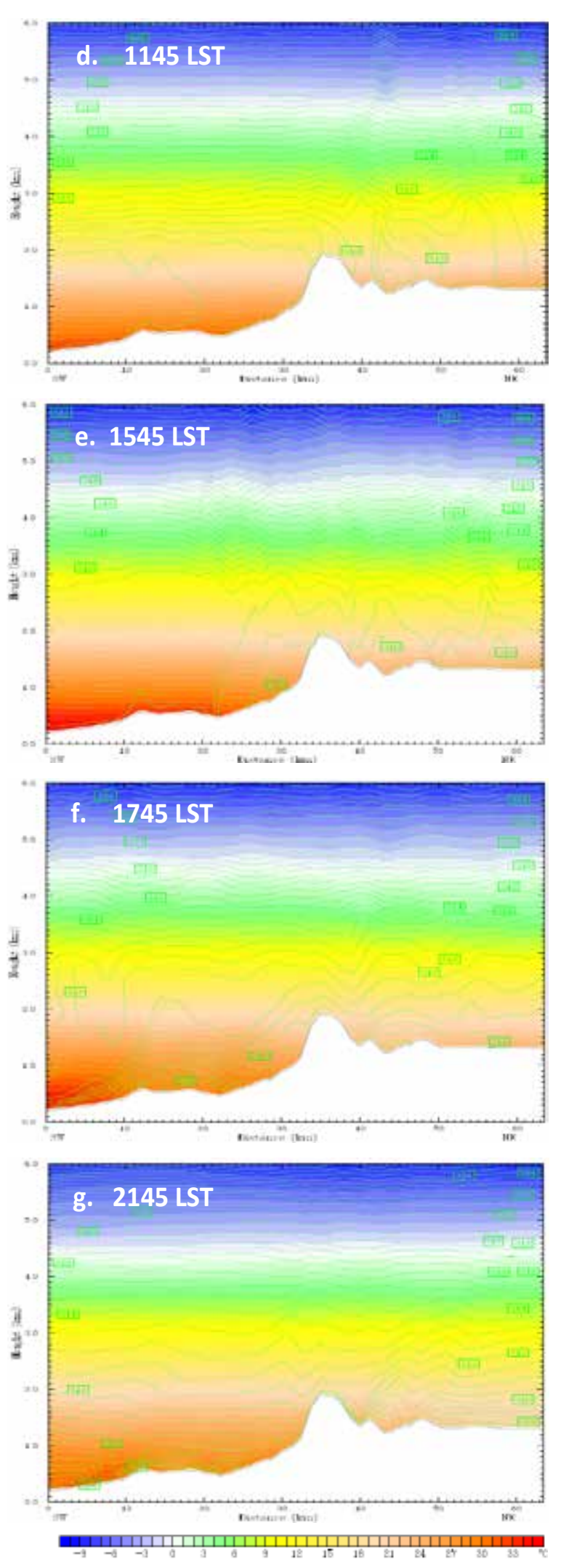

Fig. 3: Vertical cross-sectional distributions of temperature along the line $\mathrm{A}-\mathrm{B}$ that joins Kathmandu and Hetauda. 
As the solar insolation increases, the thermals of warm air over the Kathmandu valley grow quickly leading to the evolution of mixing height over both the Kathmandu valley and over the southern plain including the Hetauda valley (see Figure 3c). In the afternoon (see Figure 3d-e) the mixing height over Hetauda and the Kathmandu valleys may reach up to 2 and $1 \mathrm{~km}$, respectively. The development of relatively higher mixing layer heights over the Hetauda and Kathmandu valley allows intruding relatively cooler upper air down into the Kathmandu valley as plain-to-plateau wind, particularly, through the mountain gaps along with the valley wind from lowlands. The maximum temperature over the Hetauda valley remains to be about $33^{\circ} \mathrm{C}$ and close to $25^{\circ} \mathrm{C}$ over the Kathmandu valley. The present study also depicts that the southwestern region is relatively cooler than the central (Fig e-f) which is very consistent with the result of Regmi et.al, 2003. From the southern plain to the valley, temperature goes on decreasing with increasing altitudes and close to four kilometer above the sea level there exists a thin layer of persistence isothermal air whose temperature reaches $0^{\circ} \mathrm{C}$ (Fig. $3 \mathrm{a}-\mathrm{g}$ ) which further reduces as we ascend.

\section{CONCLUSIONS}

The intrusion moisture over the Kathmandu valley from the southern plain through the southwestern mountain appears to be appreciable. The southwestern part of the valley is predicted to be rather cooler and humid compared to central part of the valley, possibly, due to the transport of moisture and cool plain-to-plateau wind intruding from the southwestern mountain gap. Besides, the late afternoon time rainfall over the valley can be expected due to the transport of moist air from southern lowland as revealed by the present study. A long-term simulation and detail field observations are desired to quantify the amount of moisture transport from southern plain up into the Kathmandu valley.

\section{ACKNOWLEDGEMENTS}

This work is one of the outcomes of University Grant Research Project, 2011 awarded by The University Grants Commission, Nepal. The author would like to acknowledge Prof. Ram P. Regmi, lead scientists of NARERL, Central Department of Physics for his supervisions and guidance to make this work success.

\section{REFERENCES}

1. Regmi, R. P., T. Kitada, and G. Kurata, 2003: Numerical simulation of late wintertime local flows in the Kathmandu valley, Nepal: Implication for air pollution transport. J. Appl. Meteo., 42, 389-403.

2. S. Acharya, S. Neupane, R. Shrestha, C. Chapagain,S.MaharjanandR. Regmi,2014:Early Monson Time Local Flow Characteristics over the Hetauda Valley and its Implications.Journal of Science and Technology , 19(2): 109-117.

3. Sangeeta Maharjan and Ram P. Regmi, 2014: Grid Based Temperature and Relative Humidity Distribution Map of the Kathmandu Valley. Journal of Science and Technology, 19(1): 7-13.

4. Skamarock, W. C., and Coauthors, 2008: A description of theAdvance ResearchWRFversion 3. NCAR Tech. Tep. TN-475+STR, 113 pp. 